\title{
DOCKING, SYNTHESIS, CHARACTERIZATION AND ANTICANCER ACTIVITY OF 4-(4'- HYDROXY, 3'-METHOXY) PHENYL, BUT-2-ONE-3-ENE, A CURCUMIN ANALOGUE PRECURSOR
}

\author{
KARPAKAVALLI M. ${ }^{*}$, PREETHI KUMAR ${ }^{2}$, SANGLIMUTHU A. ${ }^{3}$, KUMAR E. P. ${ }^{4}$ \\ ${ }^{* 1}$ Karpagam College of Pharmacy, Coimbatore 641032, Tamilnadu, India, 2JSS College of Pharmacy, Ooty 643001, Tamilnadu, India, \\ ${ }^{3}$ Karpagam University, Coimbatore 641021 Tamilnadu, India, ${ }^{4} \mathrm{Nehru}$ College of Pharmacy, Thrissur 680001, Kerla, India \\ Email: sreemenakag@gmail.com
}

Received: 25 Jul 2016, Revised and Accepted: 05 Sep 2016

\begin{abstract}
Objective: Curcumin, a phytoconstituent of Curcuma longa has pursued the attention of research chemists, as it is found to possess a number of pharmacological activities. Autodock is an automated procedure for predicting the interaction of ligands with biomacromolecular targets. 4-(4'hydroxy, 3'-methoxy) phenyl, but-2-one-3-ene, a curcumin analog precursor is aimed to be synthesized and tested for anticancer activity.

Methods: Autodock software utilized for the prediction of the fruitfulness of the target molecule. The aldol reaction is a powerful means of forming carbon-carbon bonds in organic chemistry. Aldol condensation of monocarbocyclic aldehyde and the enol form of a 2, 4-diketone in the presence of an organic amine catalyst, the principle is used for the synthesis of said molecule. The invention also relates to the use of the synthesized product for in vivo acute toxicity and in vitro anticancer activity.

Results: The synthesized compound was characterized both by physical and spectral data. In acute toxicity study, no mortality and thereby no toxic effect from the compound (500-62.5 $\mu \mathrm{g} / \mathrm{ml})$. Against MCF-7, the test drug exhibited potent cytotoxicity with $\mathrm{CTC}_{50}$ values ranging from 42.0 to 89.0 when tested with drug concentrations ranging from 500-62.5 $\mu \mathrm{g} / \mathrm{ml}$ and average CTC50 was $125 \mu \mathrm{g} / \mathrm{ml}$ while with Vero cell line the compound showed mild cytotoxicity.
\end{abstract}

Conclusion: The experiments confirmed the fact of reliability of the synthesized compound 4-(4'-hydroxy, 3'-methoxy) phenyl, but-2-one-3-ene, a curcumin analog precursor for anti-cancer activity.

Keywords: Curcumin analogue, Docking, Synthesis, Characterization, Acute toxicity, Anti-cancer activity

(C) 2016 The Authors. Published by Innovare Academic Sciences Pvt Ltd. This is an open access article under the CC BY license (http://creativecommons.org/licenses/by/4.0/) DOI: http://dx.doi.org/10.22159/ijcpr.2016v8i4.15266

\section{INTRODUCTION}

Curcumin is a yellow pigment extracted from the rhizome of the plant Curcuma longa. The compound has been found to have a number of pharmacological activities in treating Alzheimer's disease [1], neuroprotective [2], anti-ageing effects [3], anti-tumor agents, an inhibitor of angiogenesis and as antioxidant [4], anti-inflammatory activity [5], and modulation of angiogenesis [6]. Curcumin has been demonstrated to down-regulate the expression of tubulin genes in HT-29 and Caco-2 colon cancer cells [7]. Curcumin treatment also leads to the formation of monopolar mitotic spindles in MCF-7 cancer cell lines which were incapable of chromosomal segregation [8], as amyloid beta oligomers and fibrils inhibitors [9], anticancer activity [10-13]. Clinical trials with curcumin have shown that the compound is not only safe but may be chemoprotective. The isolation of natural curcumin from the Curcuma longa rhizome has proven to be difficult and costly.

The study of the molecular interactions between biologically active natural products and the corresponding cellular receptors is of great importance from a biological as well as medicinal point of view [14]. A prerequisite for such studies are, besides the natural products themselves, appropriate analogs which, however, have to be prepared by chemical synthesis. Some more advantages of synthetic drugs over plant drugs areas: i) in synthetic drugs it is possible for the targeted drug treatment; ii) quality of the drug is completely checked; iii) side effects of the drugs were detected easily in a short duration of time and iv) duration of treatment is short. Therefore, an important research topic of our group is the rational design and the synthesis of modified analogs of curcumin [15].

In the field of molecular modeling, docking is a method which predicts the preferred orientation of one molecule to a second when bound to each other to form a stable complex. This is called as Induced fit. Molecular docking is an internet service that calculates the sites, the energy of small molecules and geometry of interacting proteins [16]. After docking simulation, well-docked protein-ligand complexes are produced in experimental laboratories for testing. Auto Dock is an automatic docking tool. It is designed to predict how small molecules, such as substrates, bind to a receptor of known 3D structures. A graphical user interface called Auto Dock Tools or ADT was utilized to generate grids, calculate the docking score and evaluate the conformers [17]. Docking is most commonly used in the field of drug design, may be applied to hit identification, lead optimization and bio-remediation.

The reaction combines two carbonyl compounds to form a new $\beta$ hydroxyl compound [18]. These products are known as aldols, the structural units seen in many important molecules, example the large-scale production of the commodity chemical pentaerythritol and the synthesis of the heart disease drug Lipitor (atorvastatin) [19]. The aldol reaction may proceed via two fundamentally different mechanisms. Carbonyl compounds, such as aldehydes and ketones, can be converted to enols or enol ethers. These compounds, being nucleophilic at the $\alpha$-carbon, can attack especially reactive protonated carbonyls such as protonated aldehydes [20]. This is the "enol mechanism." Carbonyl compounds, being carbon acids, can also be deprotonated to form enolates, which are much more nucleophilic than enols or enol ethers and can attack electrophiles directly. The usual electrophile is an aldehyde since ketones are much less reactive. This is the enolate mechanism [21].

Cancer is a complex disease involving various tempo-spatial changes in cell physiology viz., i) uncontrolled-, ii) uncoordinated-and iii) undesirable cell division, which ultimately lead to malignant tumors due to abnormal cell replication [22]. Etiological factors of cancers are mutation by chemical carcinogens, mutation by ionizing radiation, viral or bacterial infection, hormonal imbalances, immune system dysfunction, heredity and lifestyle (smoking, consumption of alcohol). Cancer presents one of the most formidable health problems worldwide. Globally every year 1.35 billion new cases are reported. In USA itself 210,000 cases reported for breast cancer in 
2009 [23]. WHO estimated that there will be 15 million new cases every year by 2020 . Cancerous diseases cause six million deaths every year, almost $12 \%$ of worldwide mortality. Lung, colorectal and stomach cancer are among both men and women. The four principal modalities utilized are surgery, radiation, chemotherapy and immunotherapy. The anticancer activity is dependent on growth fraction and mass is doubling time.

Breast cancer is cancer that starts in the breast, usually inner lining of the milk ducts or lobules. The various factors which influence the breast cancer are as follows age, race, alcohol intake, obesity, radiation, physical activity and adult height, reproductive, hereditary, hormonal, environmental and lifestyle factors [24]. Symptoms of breast cancer are the presence of lumps or thickening in the breast, swelling-, dimpling-, redness and soreness of skin, change in shape of nipple and nipple discharge. Detection and diagnosis of breast cancer can be by breast examination, mammography, ultrasound, breast MRI, fine needle aspiration, core needle biopsy, breast tumor pathology and lymph node biopsy. Treatment of breast cancer includes surgery, radiation, chemotherapy, hormonal therapy and alternative medicines.

Various compelling experimental and epidemiological studies concluded estrogen hormone as the main etiology for about $80 \%$ the breast cancer and approximately $5 \%$ of cases are due to hereditary syndromes. All the environmental and reproduction risk factors finally increase the level of this hormone [25]. This type of cancer is also known as the hormone sensitive cancers. Types of breast cancer are i) invasive-and ii) non-invasive-carcinoma, whose subtypes are (a) ductal in situ (DCIS) and (b) lobular carcinoma in situ (LCIS). Another type of breast cancer is that arises from the muscle, fat or connective tissue of the breast and is known as sarcomas.

\section{MATERIALS AND METHODS}

\section{Chemicals and instruments}

All chemicals and solvents used were of analytical grade and obtained from SD fine chemicals, Chennai, India. Melting points were determined in open capillary tubes and were uncorrected. The purity of the compounds was checked by TLC-using Silica gel-G (E-Merck). U. V. spectral studies were done on Schimadzu UV spectrophotometer (Model No. UV-2400PC). I. R. spectra were recorded in $\mathrm{KBr}$ on Schimadzu spectrophotometer; Fluorescent Microscope.

\section{Docking}

A total of 413 entries of EGFR (epidermal growth factor receptor) were selected from RCSB protein data bank, based on the presence of ligand, X-ray diffraction and $2.0-2.5 \mathrm{~A}{ }^{\circ}$ resolution. Out of the 21 entries, 2GS6 (epidermal growth factor receptor kinase) was taken for docking analysis.

A comparative protein-ligand dock analysis was performed using 2GS6 extracted from Protein Data Bank (PDB) to evaluate the algorithm and scoring function efficiency between Auto Dock 4.0.1 and experimental activities. All these computationally designed molecules, as well as the bound ligand of the protein 2GS6, were docked by using the software Auto Dock and the score values are predicted. The protein-ligand interactions were also studied in web server. Based on the score values against the activity in $\mu \mathrm{M}$ the molecules were represented as active, moderately active and inactive.

All molecules were drawn using integrated Chem Draw tool energy minimized using Tsar Software. Automated docking was used to locate the appropriate binding orientations and conformations of various inhibitors into the 2GS6 binding pocket. To perform the task, the powerful genetic algorithm method implemented in the program Auto Dock 4.0.1 was employed.

All water molecules were removed from the original Protein Data Bank file. Polar hydrogen atoms and Kollman charges 30.41 were added. Grid maps were generated by Auto Grid program. Each grid was centered at the crystal structure of the corresponding 2GS6 bound ligand. The grid dimensions were $60 \mathrm{~A}^{\circ} \mathrm{X} 60 \mathrm{~A}^{\circ} \mathrm{X} 60 \mathrm{~A}^{\circ}$ with points separated by $0.375 \mathrm{~A}^{\circ}$.
Lipinski rule of 5 (Molecular mass less than 500 Dalton; High lipophilicity-LogP less than 5; Less than 5 hydrogen bond donors; Less than 10 hydrogen bond acceptors and Molar refractivity should be between 40-130) helps in distinguishing between a drug like and non-drug like molecules [14] (tables 1and 2). It predicts a high probability of success or failure due to drug-likeness for molecules complying with 3 or more of the following rules. These filters help in the early preclinical development and could help avoid costly latestage preclinical and clinical failures. In this study, we also calculated all five parameters for all the designed compounds.

\section{Synthesis of 4-(4'-hydroxy, 3'-methoxy) phenyl, but-2-one-3-ene}

In a $500 \mathrm{ml}$ round-bottomed flask placed a cold solution of sodium hydroxide $(25 \mathrm{~g})$ in distilled water $(250 \mathrm{ml})$ and ethanol $(200 \mathrm{ml})$. Equipped the flask with a mechanical stirrer and surrounded that with a bath of distilled water. Maintained the temperature of the solution at $20-25{ }^{\circ} \mathrm{C}$ and stirred vigorously. Added one-half of a previously prepared mixture of vanillin (38 g; $0.25 \mathrm{~mol}$ ) and Acetone ( $9 \mathrm{ml} ; 0.125 \mathrm{~mol}$ ). A flocculent precipitate was formed in 2-3 min. The remainder portion of the vanillin and acetone mixture was added after $15 \mathrm{~min}$. The stirring was continued for a further $30 \mathrm{~min}$. The resultant was filtered at the pump and washed with cold water to eliminate the alkali. The reaction was monitored by TLC using the mobile phase i) Distilled water: Methanol (2:1 v/v) and ii) Methanol: Ethyl acetate $(4: 6 \mathrm{v} / \mathrm{v})$. The crude product was re-crystallized with hot ethyl acetate to afford a pure curcumin analogue. The product was confirmed by comparison with an authentic sample. The yield and all the other physical data of the synthesized curcumin analogue are given in table 3 . The UV, IR, ${ }^{1}$ HNMR and Mass spectral data and the results were given in table 4 .

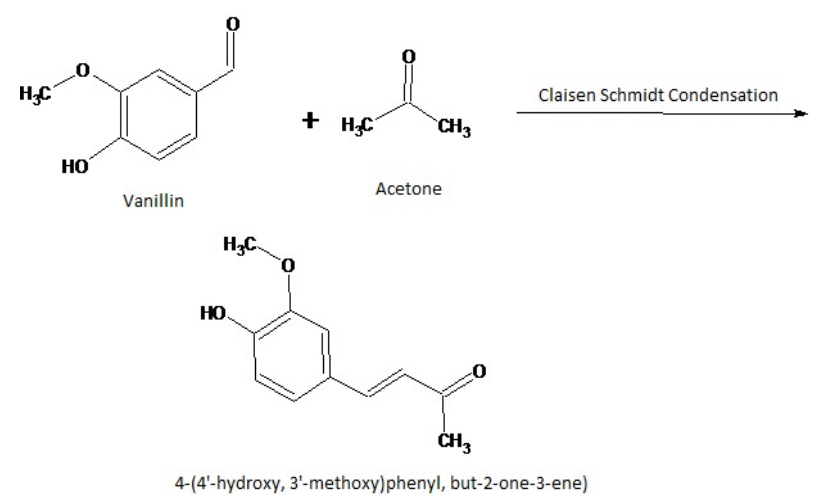

Fig. 1: Scheme of the work

\section{Acute oral toxicity study [26]}

OECD-423 guideline and acute toxic class method were followed for the acute toxicity study. Swiss albino mice of age 8-12 $\mathrm{w}$ and weight 20-25 gms were the animals of choice. The conditions maintained were humidity (30-70\%); temperature $22^{\circ} \mathrm{C}\left( \pm 3{ }^{\circ} \mathrm{C}\right)$ and lighting as $12 \mathrm{~h}$ dark and $12 \mathrm{~h}$ daylight. The animals were fed with standard pellet diet and water ad libitum.

The animals were grouped such as to contain 3 animals per group. The animals should be kept fasting (but free access to water) $4 \mathrm{~h}$ prior to the treatment. The drug substance in concentration 5, 50, 300 and $2000 \mathrm{mg} / \mathrm{kg}$ was suspended in $0.5 \%$ CMC and administered by oral route. The dose is gradually increased with each step starting with $5,50,300$ and $2000 \mathrm{mg} / \mathrm{kg}$.

Animals are observed individually after dosing at least once during the first $30 \mathrm{~min}$, periodically during the first $24 \mathrm{~h}$, with special attention given during the first $4 \mathrm{~h}$ and daily thereafter, for a total of $14 \mathrm{~d}$. Observations should include any changes in skin and fur, eyes and mucous membranes, respiratory, circulatory, and autonomic and central nervous systems, and somatomotor activity and behavior pattern. Attention should be directed to observations of mortality, tremors, convulsions, salivation, diarrhoea, lethargy, sleep 
and coma. If mortality was observed in $2 / 3$ or $3 / 3$ animals, then the dose administered was assigned as the toxic dose $\left(L D_{50}\right)$, mortality observed in one animal out of three animals, then the same dose was repeated again to confirm the toxic effect. If mortality is not observed in the given dose, then start the treatment with the next dose to another group and make the observations as mentioned.

\section{In vitro cytotoxicity studies}

\section{Cell line used}

Vero (African Green, Monkey Kidney) and MCF-7 (Human, Breast carcinoma); Concentration: $500-62.5 \mu \mathrm{g} / \mathrm{ml}$

\section{Cell lines and culture medium}

Vero and MCF-7 (Human, breast cancer) cell culture was procured from National Centre for Cell Sciences (NCCS), Pune, India. Stock cells of MCF-7 were cultured in DMEM supplemented with 10\% inactivated Fetal Bovine Serum (FBS), penicillin (100 IU/ml), streptomycin $(100 \mu \mathrm{g} / \mathrm{ml})$ and amphotericin $\mathrm{B}(5 \mu \mathrm{g} / \mathrm{ml})$ in an humidified atmosphere of $5 \% \mathrm{CO}_{2}$ at $37^{\circ} \mathrm{C}$ until confluent. The cells were dissociated with TPVG solution $0.2 \%$ trypsin, $0.02 \%$ EDTA, $0.05 \%$ glucose in Phosphate Buffer Saline). The stock cultures were grown in $25 \mathrm{~cm}^{2}$ culture flasks and all experiments were carried out in 96 microtitre plates (Tarsons India Pvt. Ltd., Kolkata, India).

\section{Determination of total cell protein content by sulphorhodamine B (SRB) assay [27]}

SRB is a bright pink amino xanthene dye with two sulfonic groups. Under mild acidic conditions, SRB binds to protein basic amino acid residues in Trichloroacetic acid (TCA) fixed cells to provide a sensitive index of cellular protein content that is linear over a cell density range of at least two orders of magnitude.

Color development in SRB assay is rapid, stable and visible. The developed colour can be measured over a broad range of visible wavelength in either a spectrophotometer or a 96 well plate reader. When TCA-fixed and SRB stained samples are air-dried, they can be stored indefinitely without deterioration.

\section{Requirements}

Confluent monolayer cell cultures; TPVG solution; DMEM with antibiotics; Newborn calf serum/sheep serum; Microtitre plates (96 well); Drug dilutions; SRB dye (0.4 \% prepared in $1 \%$ acetic acid); $10 \mathrm{mmol}$ Tris base; $50 \%$ trichloroacetic acid and microplate reader (ELISA Reader, Bio-rad).

\section{Procedure}

The monolayer cell culture was trypsinized and the cell counts adjusted to $1.0 \times 10^{5} \mathrm{cells} / \mathrm{ml}$ using growth medium. To each well of a 96 well microtitre plate, $0.1 \mathrm{ml}$ of the diluted cell suspension (approximately 10,000 cells/well) was added. After $24 \mathrm{~h}$, when a partial monolayer was formed, the supernatant was flicked off; the monolayer was washed once, and $100 \mu \mathrm{l}$ of drug dilution prepared in maintenance media was added per well in microtitre plates. The plates were then incubated at 37 ${ }^{\circ} \mathrm{C}$ for $3 \mathrm{~d}$ in $5 \% \mathrm{CO}_{2}$ atmosphere, and microscopic examination was carried out, and observations recorded every $24 \mathrm{~h}$.

After $72 \mathrm{~h}, 25 \mu \mathrm{l}$ of $50 \%$ trichloroacetic acid was added to the wells gently such that it forms a thin layer over the drug dilutions to form an overall concentration of $10 \%$. The plates were then incubated at $4{ }^{\circ} \mathrm{C}$ for $1 \mathrm{~h}$. The plates were flicked; culture was washed five times with tap water to remove traces of medium, drug, and serum, and was then air-dried. The air-dried plates were stained with SRB for $30 \mathrm{~min}$. The unbound dye was then removed by rapidly washing four times with $1 \%$ acetic acid. The plates were then air-dried. 100 $\mu \mathrm{l}$ of $10 \mathrm{mmol}$ tris base was then added to the wells to solubilize the dye. The plates were shaken vigorously for $5 \mathrm{~min}$. The absorbance was measured using microplate reader at a wavelength of $540 \mathrm{~nm}$.

\section{CALCULATION}

The percentage growth inhibition was calculated using the following formula and concentration of test drug needed to inhibit cell growth by $50 \%\left(\mathrm{CTC}_{50}\right)$ values is generated from the dose-response curves for each cell.
$\%$ Growth inhibition $=100-\frac{\text { Mean OD of individual test group }}{\text { Mean OD of Control group }} \times 100$

\section{RESULTS}

Computational strategies for structure-based drug discovery offer a valuable alternative to the costly and time-consuming process of random screening. Auto Dock is employed to study the docking molecules within active site region of $2 \mathrm{GS6}$ and Accelrys, DS visualizer 2.0 is used to studying the H-bond interaction. At the end of each run, docked orientations are saved, and the resultant molecules are checked for geometry and number of hydrogen bonds.

In silco molecular analysis of six different analogues of 4-oxy quinazoline urea derivatives has been done, all these compounds obeyed 'Lipinski rule of 5'. These analogues are taken for computing molecular descriptors, and then for synthesis.

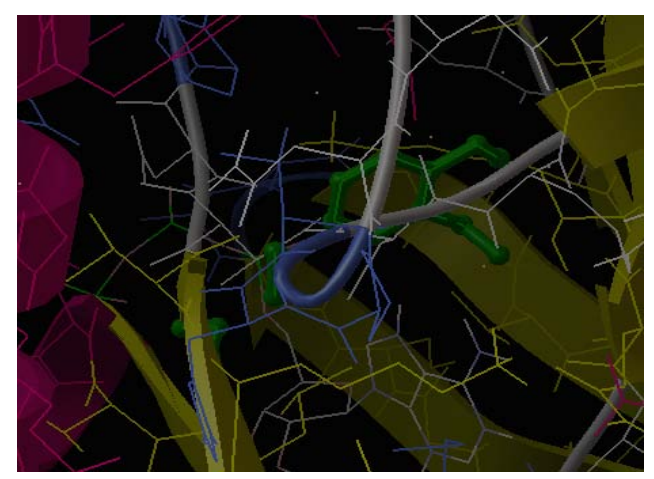

Fig. 2: Protein and ligand (the newly designed molecule) interacted matrix

The newly designed molecules were docked against the protein 2GS6 and the docking score is along with inhibition constant (Ki) were reported in table 1 and it became evident that the newly designed molecules have docked scores more than $-4.16 \mathrm{kcal} / \mathrm{mol}$ which is the docked score of 2GS6. Fig. 1 shows the interaction mode of the compound with 2GS6 receptor site. Computationally designed ligands were pre-filtered for their drug-like properties by lipinski's rule. Lipinski's rule of five was calculated for all the eight ligand molecules that satisfy the 'rule of-5' and it was found that all the ligand molecules satisfied the rule for potent promoters as shown in table 2 .

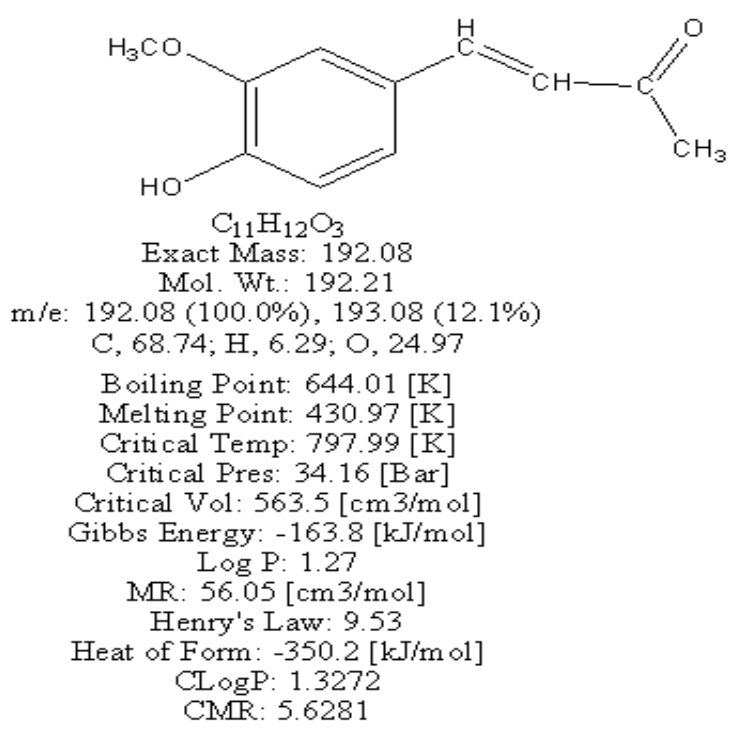

Fig. 3: Structure and Auto-docking data of the newly designed molecule 
Table 1: Docking score and constant inhibition details of the newly designed molecule

\begin{tabular}{lllll}
\hline Compound & Auto dock score (K Cal/mol) & Ki $(\boldsymbol{\mu M})$ & No. of H bonds & Interacting residues \\
\hline $\mathrm{C}_{11} \mathrm{H}_{12} \mathrm{O}_{3}$ & 4.81 & 299.66 & 2 & ARG817 \\
\hline
\end{tabular}

Table 2: Parameters confirming that the newly designed molecules satisfying the "Rule of 5"

\begin{tabular}{lllllll}
\hline Compound & Mol. Wt. & Log P & -H bond donor & -H bond acceptor & Molar refractivity & Number of criteria met 15 \\
\hline Rule & $<500$ & $<5$ & $<5$ & $<10$ & $40-130$ & At least 3 \\
$\mathrm{C}_{11} \mathrm{H}_{12} \mathrm{O}_{3}$ & 192 & 1.27 & 1 & 1 & 56.05 & ALL \\
\hline
\end{tabular}

In the molecular docking study, the compound Qd showed good binding interaction with HER3, Servivin, Estrogen, CDK1. Qc showed a good binding with EGFR, Cyclin kinase, and AKT1. Qe having a good binding with $\operatorname{COX} 2, \mathrm{Qa}, \mathrm{Qb}$ and $\mathrm{Qf}$ having a moderate binding. This is comparable to the standard natural ligand. So these compounds can be taken for further studies as anticancer agents. From the above results, we can expect that these compounds may prove beneficial in the near future as anticancer drugs along with other rationally designed drugs like Gefitinib, Loratinib, Thymitaq, etc.,

Among the various parent nucleus, quinazoline nucleus has been reported to having a potent anticancer activity which has a target specific activity especially the EGFR in the breast cancer conditions. Hence the present study was concerned on the synthesis of the quinazolin-4-one derivative with the aromatic substitution at the fourth position.
The compound of a curcumin analog precursor was synthesized by reported literature method. Our route of synthesis of curcumin analog was shown in scheme-1. The compound 4-(4'-hydroxy, 3'methoxy) phenyl, but-2-one-3-ene, a curcumin analogue precursor was synthesized by a chemical reaction between vanillin and acetone involving the principle of Claisen-Schmidt Condensation. The newly synthesized compound was obtained in high overall yield (93\%) from vanillin. The reaction worked well and thus; the present method provides a new analogue of curcumin base.

The synthesized compound was tested by ferric chloride test, with bromine water, tollen's test, phenyl hydrazine test and iodoform test for confirming the presence of phenolic-OH group, unsaturation, the presence of carbonyl group, the presence of conjugated $\mathrm{C}=0$ group and presence of methyl ketone in our compound. The synthesized compounds melting point were recorded by open capillary methods which are uncorrected. The melting point and percentage yield values were given in table 3 .

Table 3: Physical data of the synthesized 4-(4'-hydroxy, 3'-methoxy) phenyl, but-2-one-3-ene

\begin{tabular}{|c|c|c|c|c|c|c|c|}
\hline $\begin{array}{l}\text { S. } \\
\text { No. }\end{array}$ & Name of the compound & Molecular formula & $\begin{array}{l}\text { Mol. } \\
\text { Wt. }\end{array}$ & $\begin{array}{l}\text { Melting } \\
\text { point }{ }^{\circ} \mathrm{C}\end{array}$ & $\begin{array}{l}\text { Practical } \\
\text { yield (g) }\end{array}$ & \% yield & Rf value \\
\hline 1. & 4-(4'-hydroxy, 3'-methoxy) phenyl, but-2-one-3-ene & $\mathrm{C}_{11} \mathrm{H}_{12} \mathrm{O}_{3}$ & 192 & More than 240.0 & 0.850 & 93.0 & 0.42 \\
\hline
\end{tabular}

Thin layer chromatography techniques were performed for all synthesized compounds and the parent compounds. Detection is done by using i) iodine vapor, ii) UV light (bright yellow) and iii) ammonia vapors (dull brown). All synthesized compounds were observed in a single spot whose $\mathrm{R}_{\mathrm{f}}$ values are different from their reactants. It ultimately shows that the compound's purity and completion of the reaction.

The absorption maxima, $\lambda$ max, of the synthesized compounds were recorded by using distilled water as a solvent. It proves the further confirmation of compounds. An IR spectrum was taken for the synthesized compound. The characteristic absorption peaks were observed for all relevant groups. The absorption peak around 3255 $\mathrm{cm}^{-1}$ a weak broad-OH stretch enol form; $2746 \mathrm{~cm}^{-1} \mathrm{C}-\mathrm{H}$ stretch aldehyde hydrogen weak bands; $1654 \mathrm{~cm}^{-1}$ conjugation $\mathrm{C}=0$ stretch in enol form; $1581 \mathrm{~cm}^{-1}$ aromatic $\mathrm{C}=\mathrm{C}$ conjugation; $1317-1118 \mathrm{~cm}^{-1}$ $\mathrm{C}-\mathrm{C}(=0)-\mathrm{C}$ bending appears as med-intensity peak; $1018 \mathrm{~cm}^{-1} \mathrm{C}-\mathrm{H}$ inplane bending, benzene ring; $829 \mathrm{~cm}^{-1} \mathrm{C}-\mathrm{H}$ out of plane bending, 1,3disubstituted benzene ring; $657 \mathrm{~cm}^{-1}-\mathrm{OH}$ out of plane bending, associated-OH group. The compounds' structural elucidation was done by various analytical techniques such as TLC, UV, IR, ${ }^{1}$ HNMR and Mass spectra.

Acute oral toxicity study has performed and it is found that there is no mortality and thereby no toxic effect from the compound. Mammary carcinoma results from the undifferentiated growth of mammary cells associated with different combinations such as disturbances in TCA cycle i.e. downregulation of TCA cyclic enzymes, non-glycolytic enzymes and up regulations of glycolytic enzymes. These two factors produce HIF-ALPHA and lead to induction of anti-apoptotic genes in the cell nucleus, also cause the hypoxia condition to the cell. It causes activation of angiogenesis by activation of VEGF at the same time oxidative stress and free radical reactions. With these consequences finally leads to oxidative stress resulting in increased resistance to therapy has been seen in breast cancer.

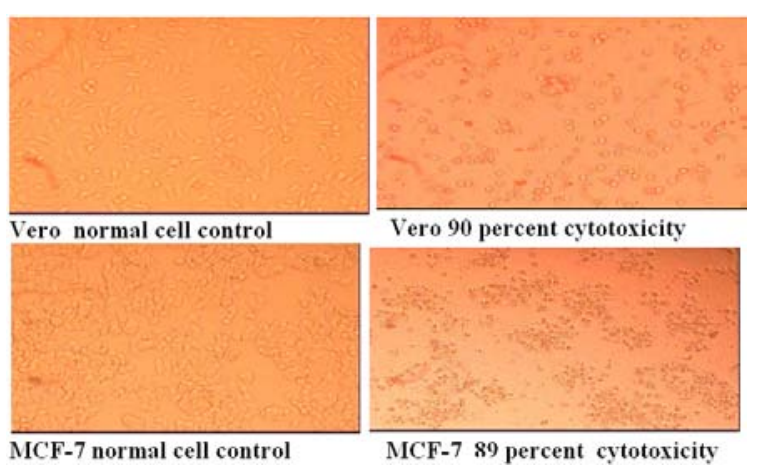

Fig. 4: Percentage cancer cells growth inhibition by vero and MCF-7 S

So the current regimen of chemotherapy has two major disadvantages, one is, it utilizes drugs which inhibit DNA synthesis, and another serious problem is the resistance of the drugs in use. Therefore there is an urgent requirement for development of new cancer drugs which overcome these disadvantages. Hence, nowadays research works carried out with synthetic compounds were concerned on alternative approach other than inhibition of DNA synthesis, one of the alternative approach used nowadays involves the evaluation of compounds involved in the inhibition of signal transduction, by substituting one or more substituents to the parent nucleus.

Against MCF-7, the test drug exhibited potent cytotoxicity with $\mathrm{CTC}_{50}$ values ranging from 42.0 to 89.0 when tested with drug concentrations ranging from $500-62.5 \mu \mathrm{g} / \mathrm{ml}$ and average CTC50 was $125 \mu \mathrm{g} / \mathrm{ml}$ while with Vero cell line the compound showed mild cytotoxicity as shown in table 4. 
Table 4: Percentage cancer cells growth inhibition by vero and MCF-7 S

\begin{tabular}{llllll}
\hline Sample & $\begin{array}{l}\text { Concentration } \\
\text { used in } \boldsymbol{\mu g} / \mathbf{m l}\end{array}$ & $\begin{array}{l}\text { \% growth } \\
\text { inhibition }\end{array}$ & $\begin{array}{l}\text { MCF-7CTC50 } \\
\boldsymbol{\mu g} / \mathbf{m l}\end{array}$ & $\begin{array}{l}\text { Concentration used in } \\
\boldsymbol{\mu g} / \mathbf{m l}\end{array}$ & $\begin{array}{c}\text { \% growth } \\
\text { inhibition }\end{array}$ \\
\hline 1 & 500 & $89 \pm 0.15$ & 1 & 500 & $90 \pm 0.09$ \\
& 250 & $71 \pm 0.07$ & 2 & 250 & $57 \pm 0.06$ \\
& 125 & $50 \pm 0.11$ & 5 & 125 & $38 \pm 0.10$ \\
& 62.5 & 42 & & 62.5 & 210 \\
\end{tabular}

Values are expressed as mean+SD; Values are from triplicate readings; and are statistically significant at $\mathrm{p}<0.05^{*}, \mathrm{p}<0.01^{* *}, \mathrm{p}<0.001^{* * *}$, when compared to the standard.

\section{ACKNOWLEDGEMENT}

The authors wish to place on record their heartfelt thanks to the Principal and the management of Karpagam College of Pharmacy, Othakalmandapam, Coimbatore-641032, India for providing the facilities to carry out the research successfully.

\section{CONFLICT OF INTERESTS}

The authors declare no conflict of interests

\section{REFERENCES}

1. Bala K. NSAID and antioxidant prevention of Alzheimer's disease: lessons from in vitro and animal models. Ann N Y Acad Sci 2006;1035:68-84.

2. Khurana S, Jain S, Banerjee BD, Sharma KK. Protective role of curcumin on colchicine-induced cognitive dysfunction and oxidative stress in rats. Human Exp Toxicol 2012;31:686-97.

3. Kiran B, Tripathy B, Sharma S, Deepak A. Neuroprotective and anti-ageing effects of curcumin in aged rat brain regions. Biogerontology 2006;7:81-9.

4. Syu Wan. Involvement of the. beta-diketone moiety in the antioxidative mechanism of tetrahydrocurcumin. Biochem Pharmacol 1998;52:519-25.

5. Sandur SK, Pandey MK, Sung B, Ahn KS, Murakami A. Curcumin, demethoxy curcumin, bisdemethoxycurcumin, tetrahydrocurcumin, and turmerones differentially regulate antiinflammatory and anti-proliferative responses through an ROS$\mathrm{n}$ dependent mechanism. Carcinogens 2007;28:1765-73.

6. Agrawal DK, Mishra PK. Curcumin and its analogues: potential anticancer agents. Res Rev 2010;30:818-60.

7. Thaloor D, Singh AK, Sidhu GS, Prasad PV, Kleinman HK Inhibition of angiogenic differentiation of human umbilical vein endothelial cells by curcumin. Cell Growth Differ 1998;9:305-12.

8. Van Erk M, Teuling E, Staal Y, Huybers S, Van Bladeren P. Time and dose-dependent effects of curcumin on gene expression in human colon cancer cells. J Carcinogene 2004;3:8.

9. Holy JM. Curcumin disrupts mitotic spindle structure and induces micronucleation in MCF-7 breast cancer cells. Mutat Res/Gene Toxicol Environ Mutagene 2002;518:71-84.

10. Fusheng Yang. Curcumin inhibits the formation of amyloid $\beta$ oligomers and fibrils, binds plaques, and reduces amyloid in vivo. J Biol Chem 2005;280:5892-901.

11. Parveen I. Synthesis and anticancer activity of nordihydroguaiaretic acid (NDGA) and analogues. Anti-Cancer Drug Design 2000;16:261-70.
12. Artiser JL. Synthesis of dibenzoyl methane derivatives and inhibition of mutagenicity in salmonella typhimurium. Chem Abstract 1998;117:480-6.

13. Ruby AJ. Antitumor-promoting effects of cyclic diarylheptanoids on epstein-barr virus activation and twostage mouse skin carcinogenesis. Canc Lett 1995;15:135-40.

14. Gautam SC. Cytotoxicity of curcuminoids and some novel compounds from curcuma zedoary. J Nat Prod 2007;61:15314.

15. Schneider G, Heinz K. Molecular design, concepts and applications. John Wiley and Sons; 2008.

16. Schames JR. Discovery of a novel binding trench in HIV integrase. J Med Chem 2004;47:1879-81.

17. Nurfina AN. Synthesis of naturally occurring curcuminoids and related compounds. Chem Abstract 1997;103:1780-92.

18. Rouset Y. Synthesis and ${ }^{1}$ HNMR-spectroscopic investigations of new curcumin analogs. J Prakt Chem 1973;334:656-700.

19. Pedersen F. Direct synthesis of demethoxy curcumin. CR. Acad Sci Paris: Ser II; 1985. p. 479-82.

20. Barry MT. Direct asymmetric Zn-aldol reaction of methyl vinyl ketone and its synthetic applications. J Am Chem Soc 2005;127:8602-3.

21. Christophe A. (Diisopinocampheyl)borane-mediated reductive aldol reactions of acrylate esters: enantioselective synthesis of anti-aldols. Org Lett 2013;15:3922-5.

22. Manabe K. Synthetic reactions using organometallics in water. Aldol and allylation reactions catalyzed by Lewis acidsurfactant-combined catalysts/Bronsted acids systems. Inorg Chim Acta 1999;26:158-63.

23. Argiles JM, Azcon-Bieto J. The metabolic environment of cancer. Mol Cell Biochem 1988;81:3-17.

24. Rudden RW. Cancer biology. $4^{\text {th }}$ edition. Oxford University Press; 2007. p. 9-20.

25. Reynolds RJ, Schecker JA. Radiation cell cycle and cancer. Loss Almos Sci 1995;23:74-6.

26. Philip S, Rista S, Dominic S, Anne M, James M. New colorimetric cytotoxic assayfor anti cancer drug screening. J Natl Cancer Inst 1990;82:1107-12.

How to cite this article

- Karpakavalli M, Preethi Kumar, Sanglimuthu A, Kumar EP. Docking, synthesis, characterization and anticancer activity OF 4(4'-hydroxy, 3'-methoxy) phenyl, but-2-one-3-ene, a curcumin analogue precursor. Int J Curr Pharm Res 2016;8(4):1-5 